\title{
LA-UR-21-30744
}

Approved for public release; distribution is unlimited.

Title: $\quad$ Robustify Your Links! For better stewardship of references to web resources in digital scholarship

Author(s): $\quad$ Klein, Martin

Intended for: $\quad$ LANL RL OA week presentation

Issued: $\quad$ 2021-10-28 
Disclaimer:

Los Alamos National Laboratory, an affirmative action/equal opportunity employer, is operated by Triad National Security, LLC for the National Nuclear Security Administration of U.S. Department of Energy under contract 89233218CNA000001. By approving this article, the publisher recognizes that the U.S. Government retains nonexclusive, royalty-free license to publish or reproduce the published form of this contribution, or to allow others to do so, for U.S. Government purposes. Los Alamos National Laboratory requests that the publisher identify this article as work performed under the auspices of the U.S. Department of Energy. Los Alamos National Laboratory strongly supports academic freedom and a researcher's right to publish; as an institution, however, the Laboratory does not endorse the viewpoint of a publication or guarantee its technical correctness. 


\section{Robustify Your Links! For better stewardship of references to web resources in digital scholarship}
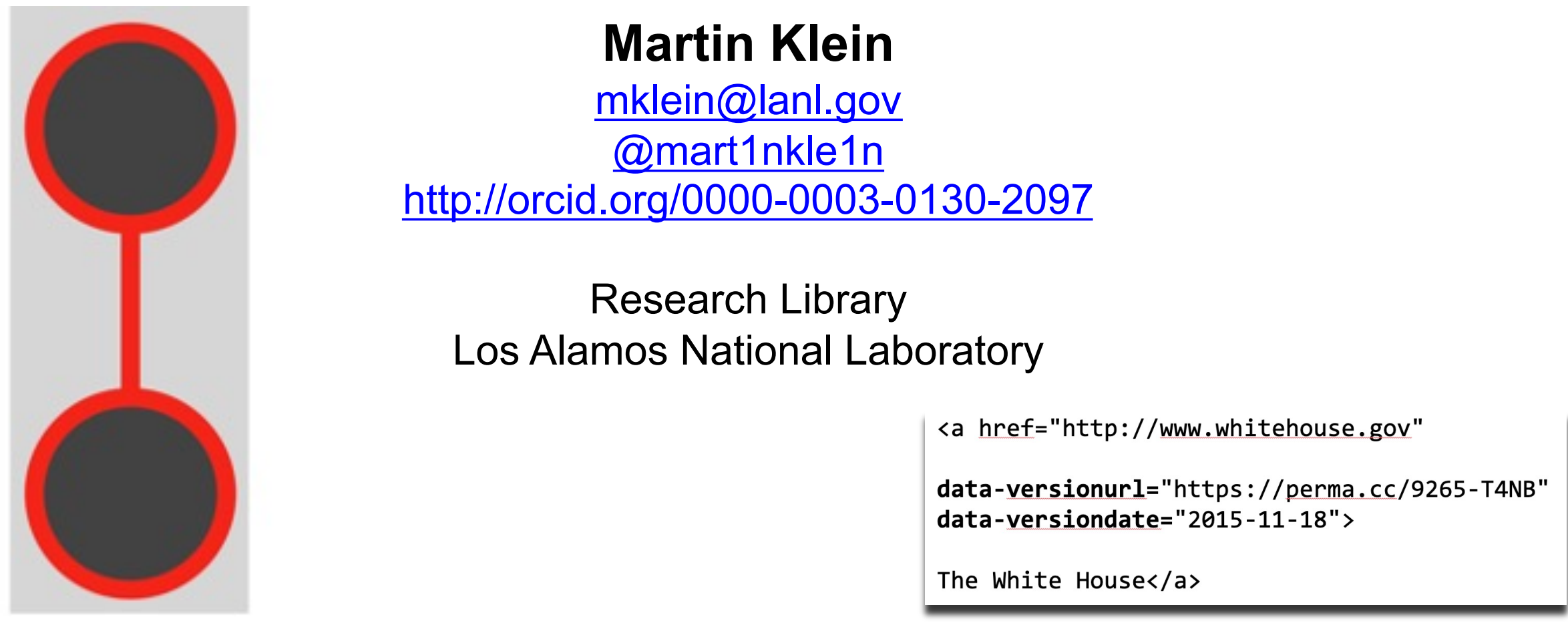


\section{Web-based scholarly communication}
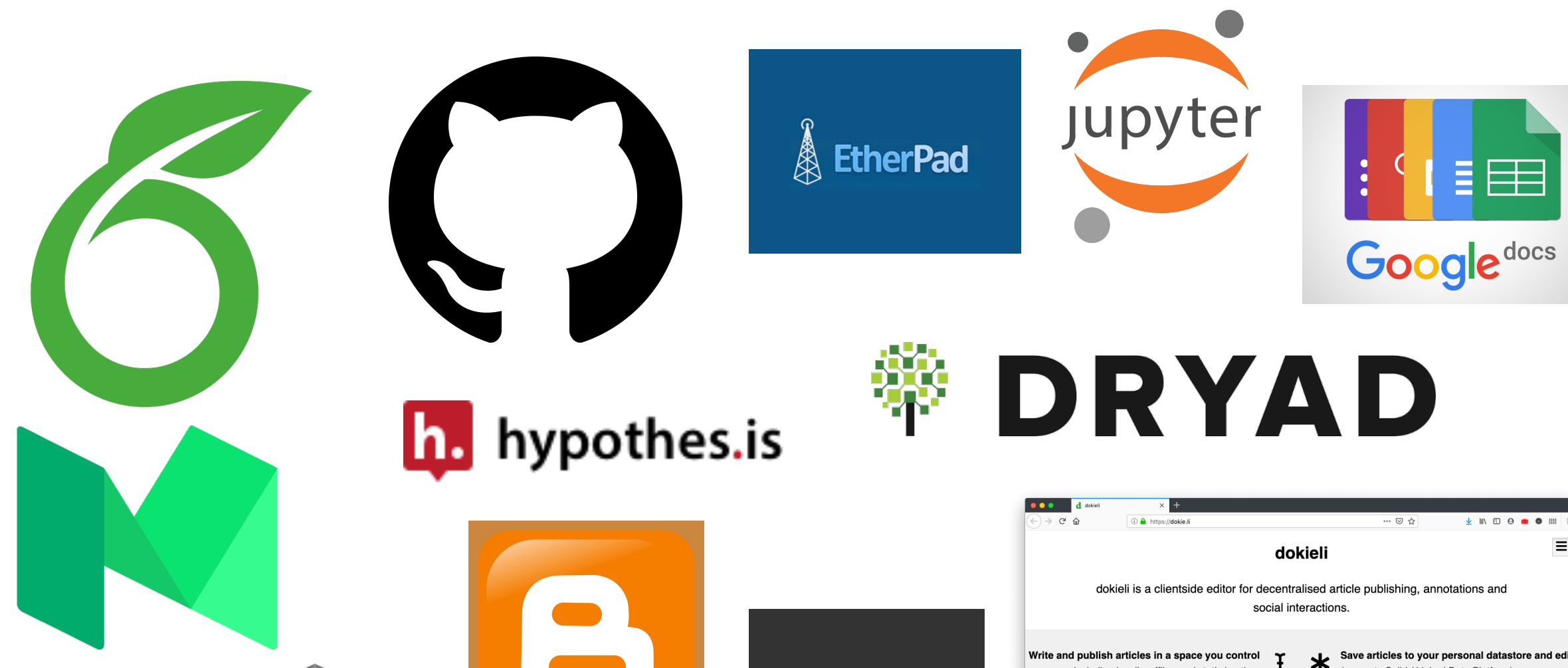

\section{Google docs}

\section{h. hypothes.is}
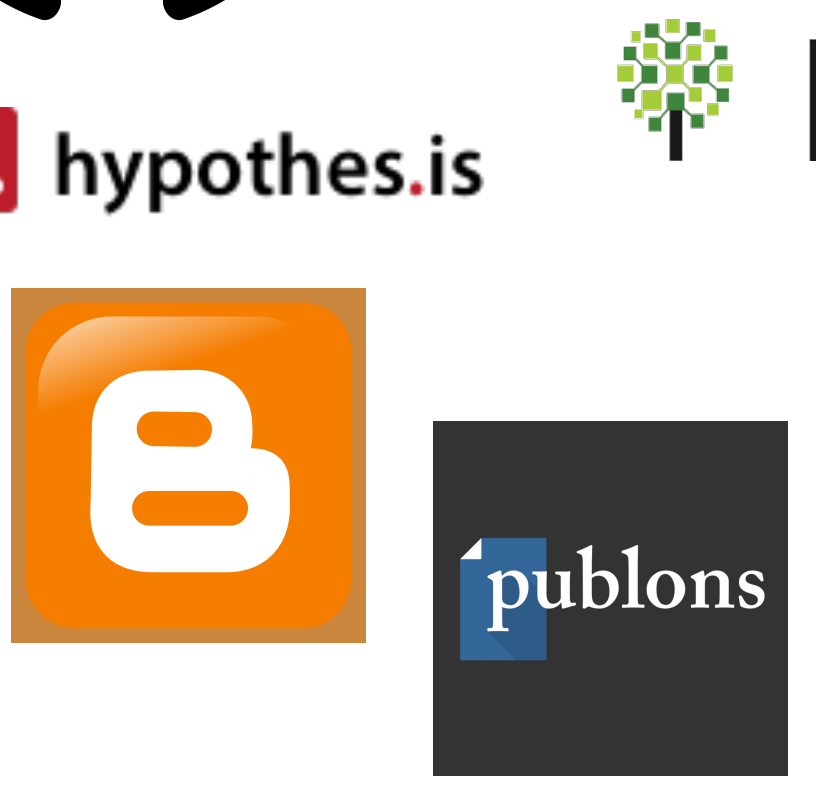


\section{Innovations in scholarly communication}

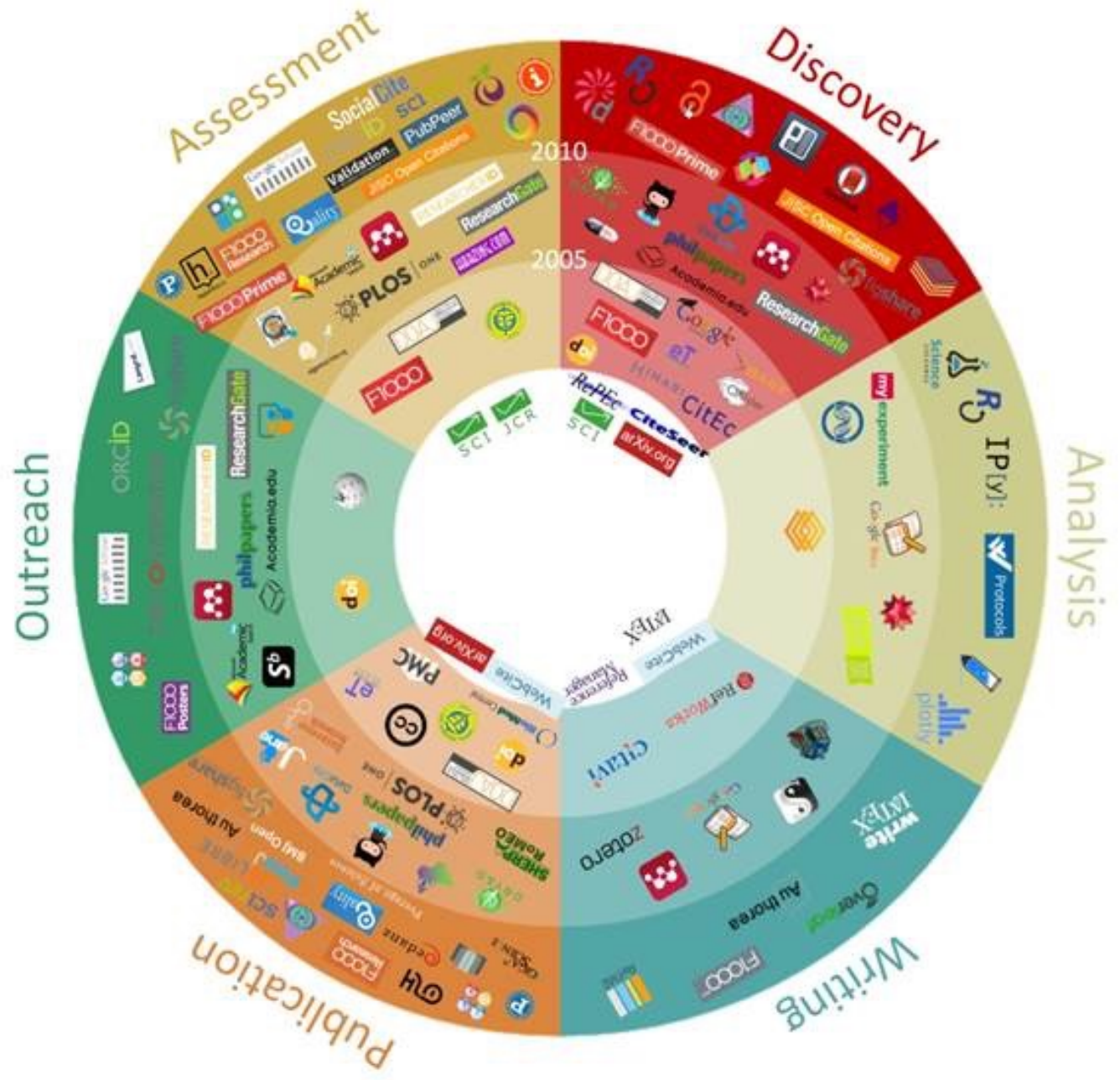

Jeroen Bosman and Bianca Kramer https://101innovations.wordpress.com/ 


\section{Scholarly communication questions}

- How does this affect our references in scholarly articles?

- Do we increasingly reference resources on the web?

- What sort of web resources do we reference?

"Scholarly Context Not Found: One in Five Articles Suffers from Reference Rot" https://doi.org/10.1371/journal.pone.0115253

"Scholarly Context Adrift: Three out of Four URI References Lead to Changed Content" https://doi.org/10.1371/journal.pone.0167475 


\section{Scholarly communication concerns}

- What happens to such references over time?

- Do they remain stable?

- Do they break?

- Does their content change? 


\section{Stable reference}

Reference URI:

http://ifa.hawaii.edu/ cowie/k table.html

Referenced in:

http://arxiv.org/abs/astro-ph/9707064

published on July 4th 1997

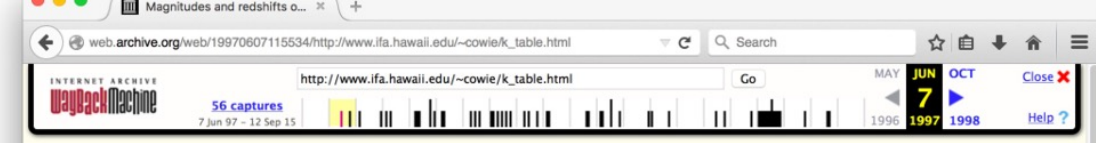

H+K ordered Table

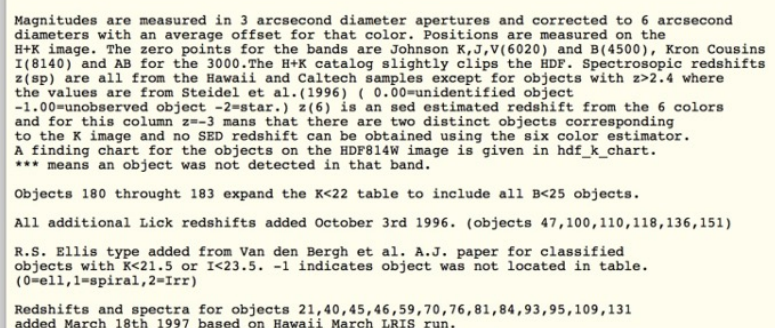

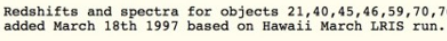

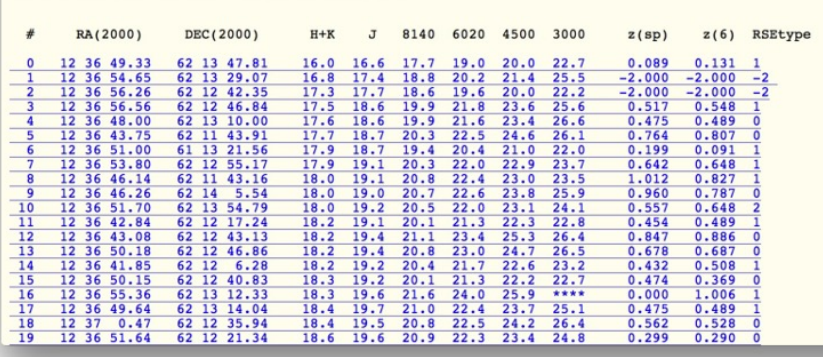

June 7th 1997

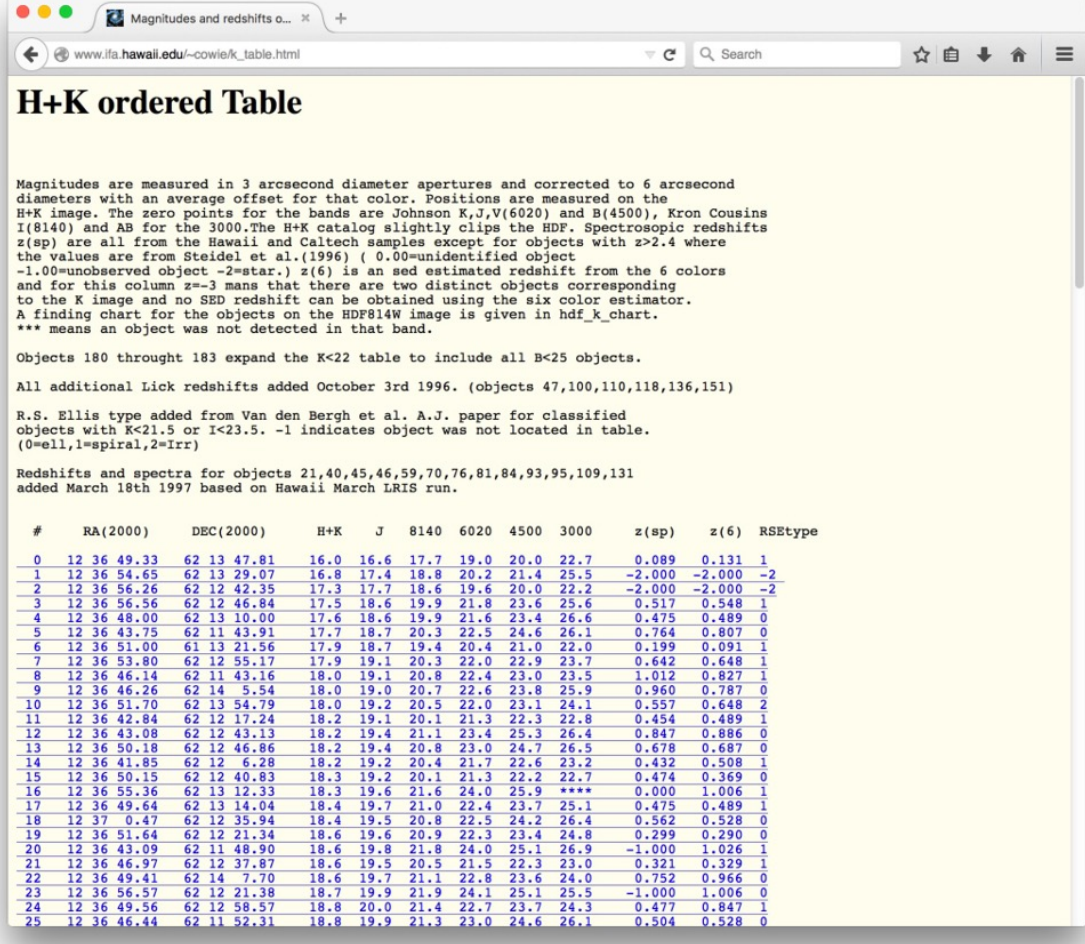

today 


\section{Link Rot}

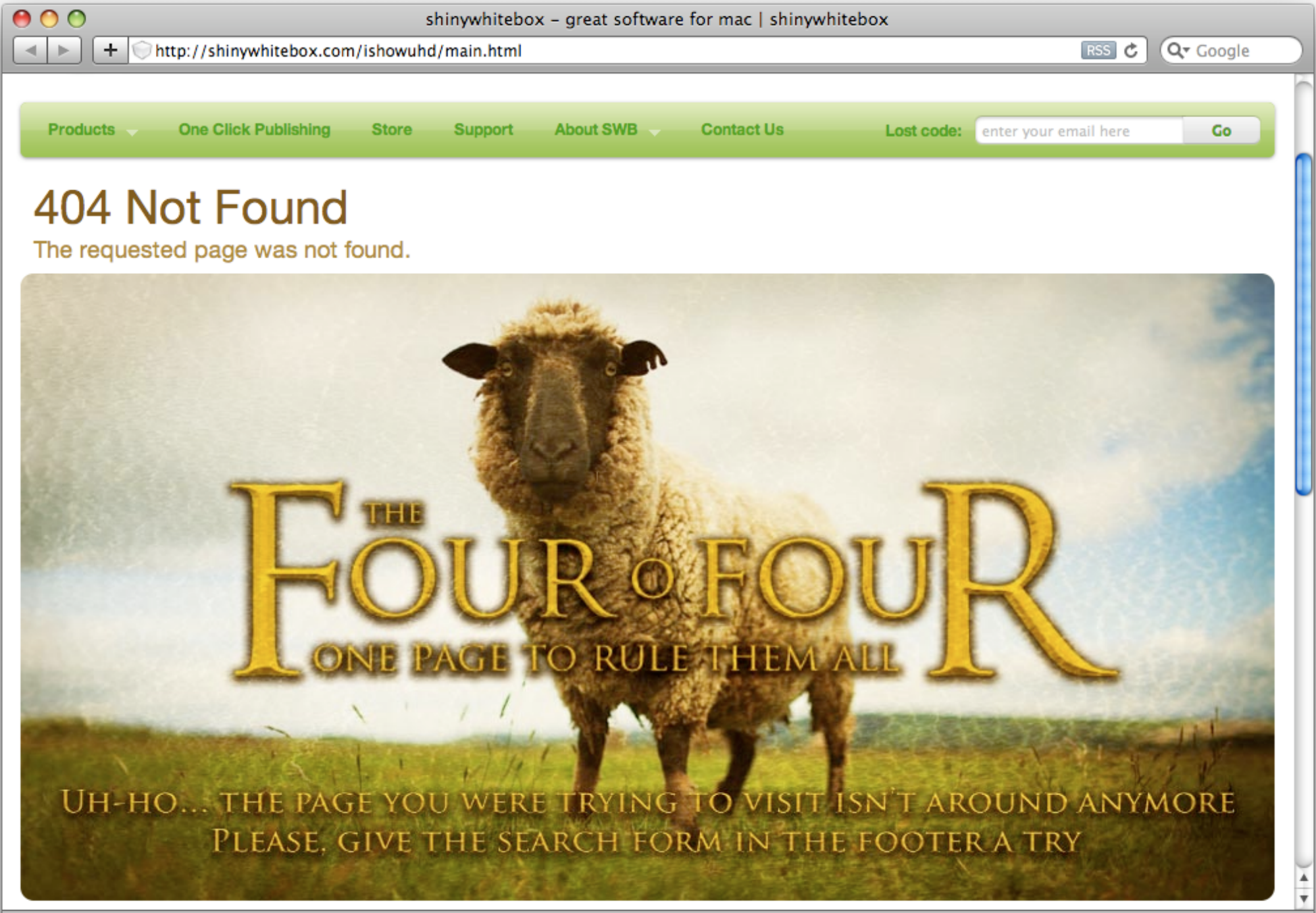




\section{Content Drift}

$\ominus \odot \odot$ 血Digital Libraries '00

C web.archive.org/web/20000621183421/http://www.dl00.org/

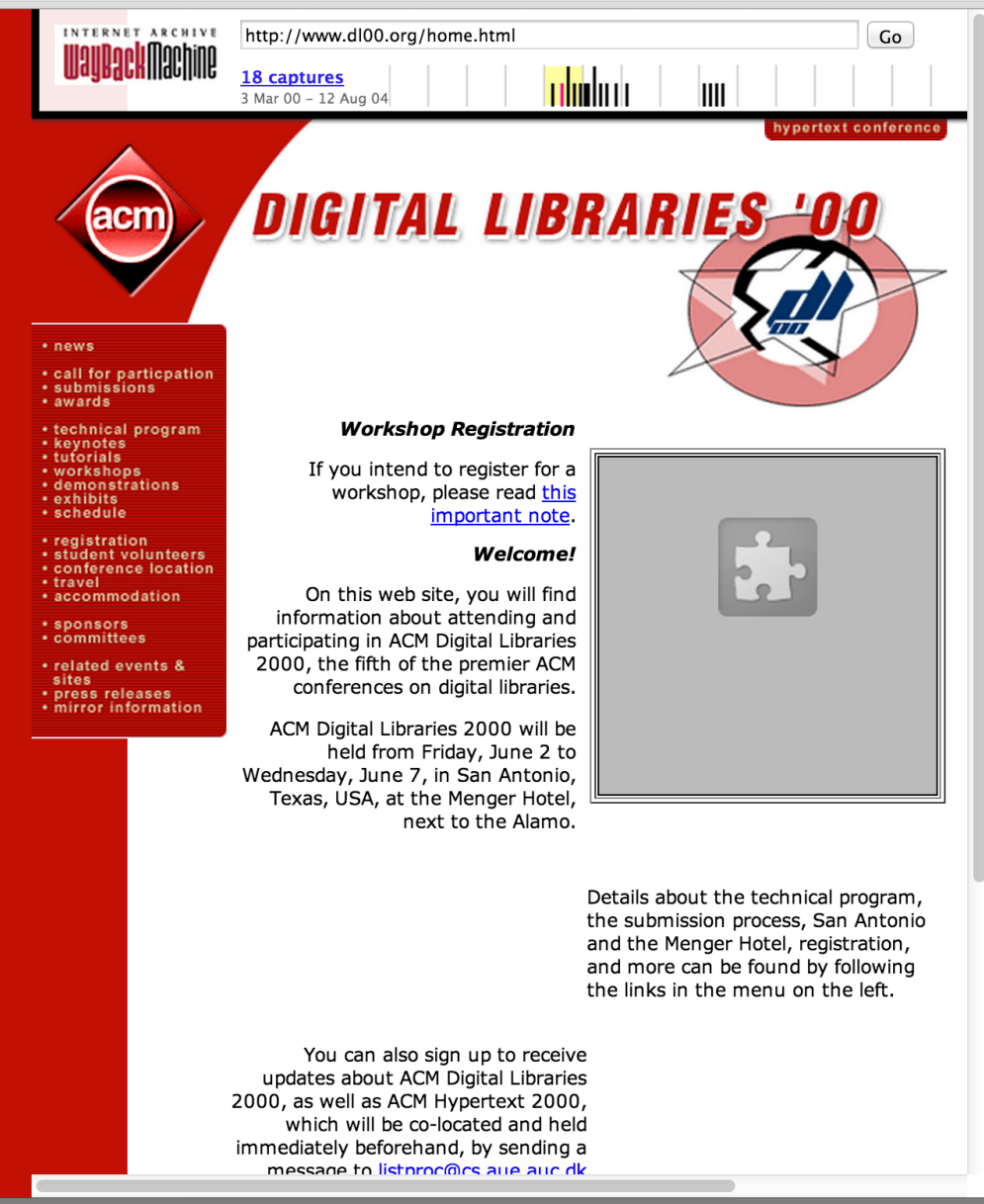

http://dl00.org

2000 


\section{Content Drift}

$\ominus \odot \odot$ 血d100.org

$\leftarrow \rightarrow$ C $\square$ web.archive.org/web/20040824033120/http://dl00.org/

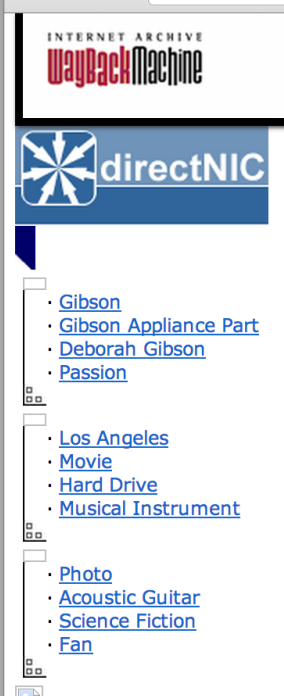

2
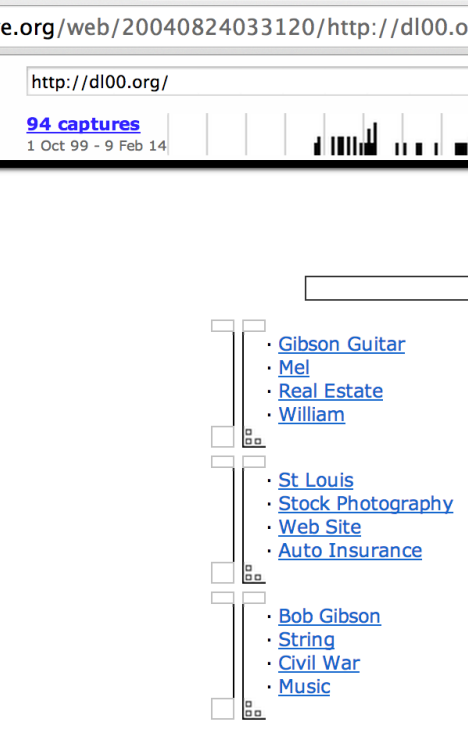

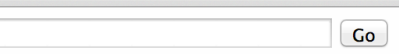

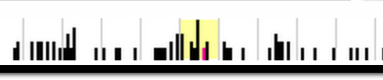
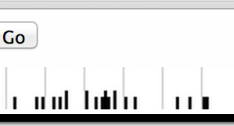

JU

JUN AUG FEB

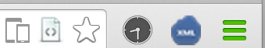

close $x$ Help ?

$2004 \lcm{2006}$

Search

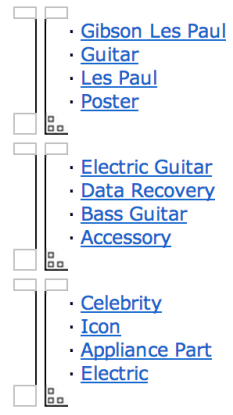

http://dl00.org

2004 


\section{Content Drift}

๑○○ 回 1936,

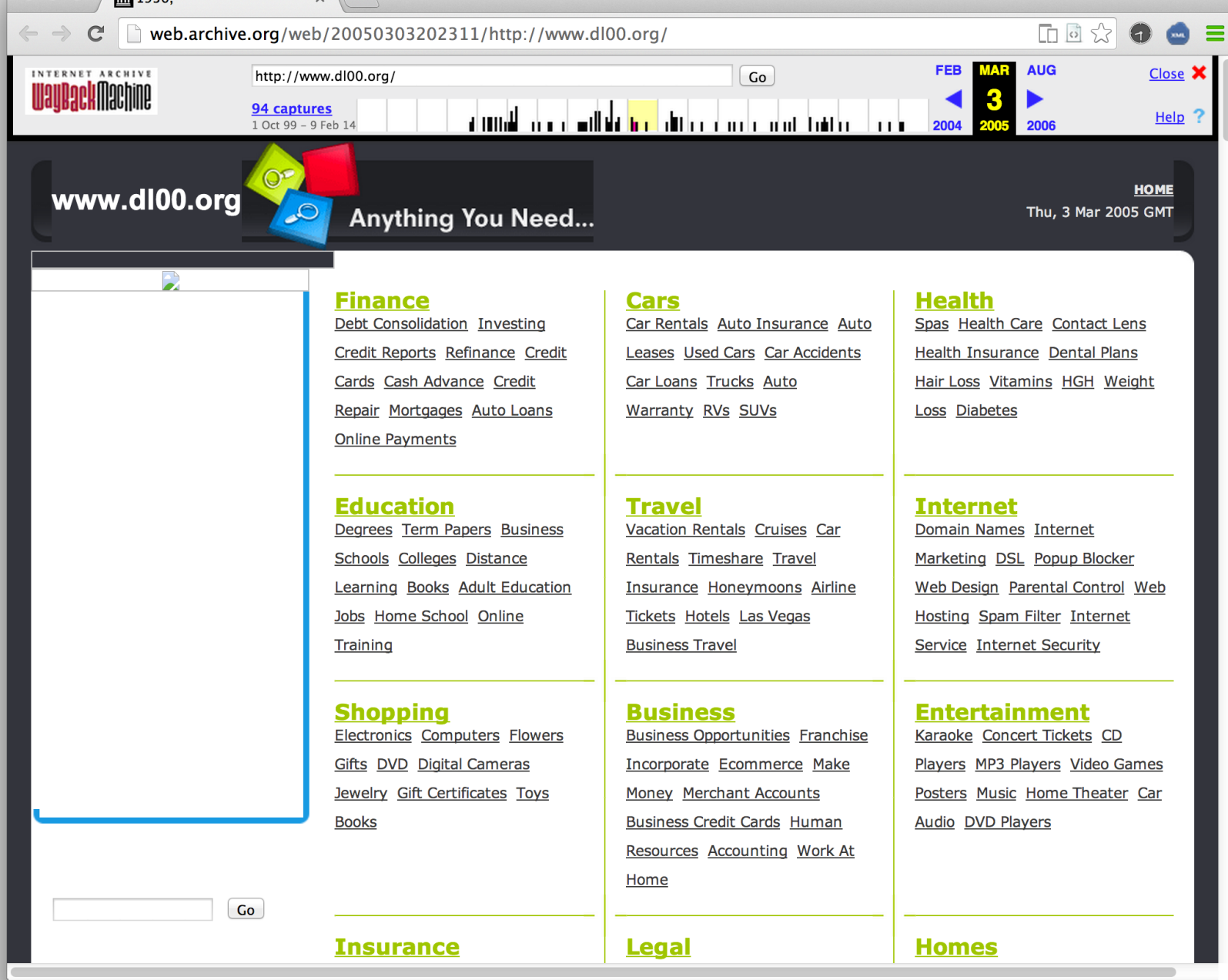

http://dl00.org

2005 


\section{Content Drift}

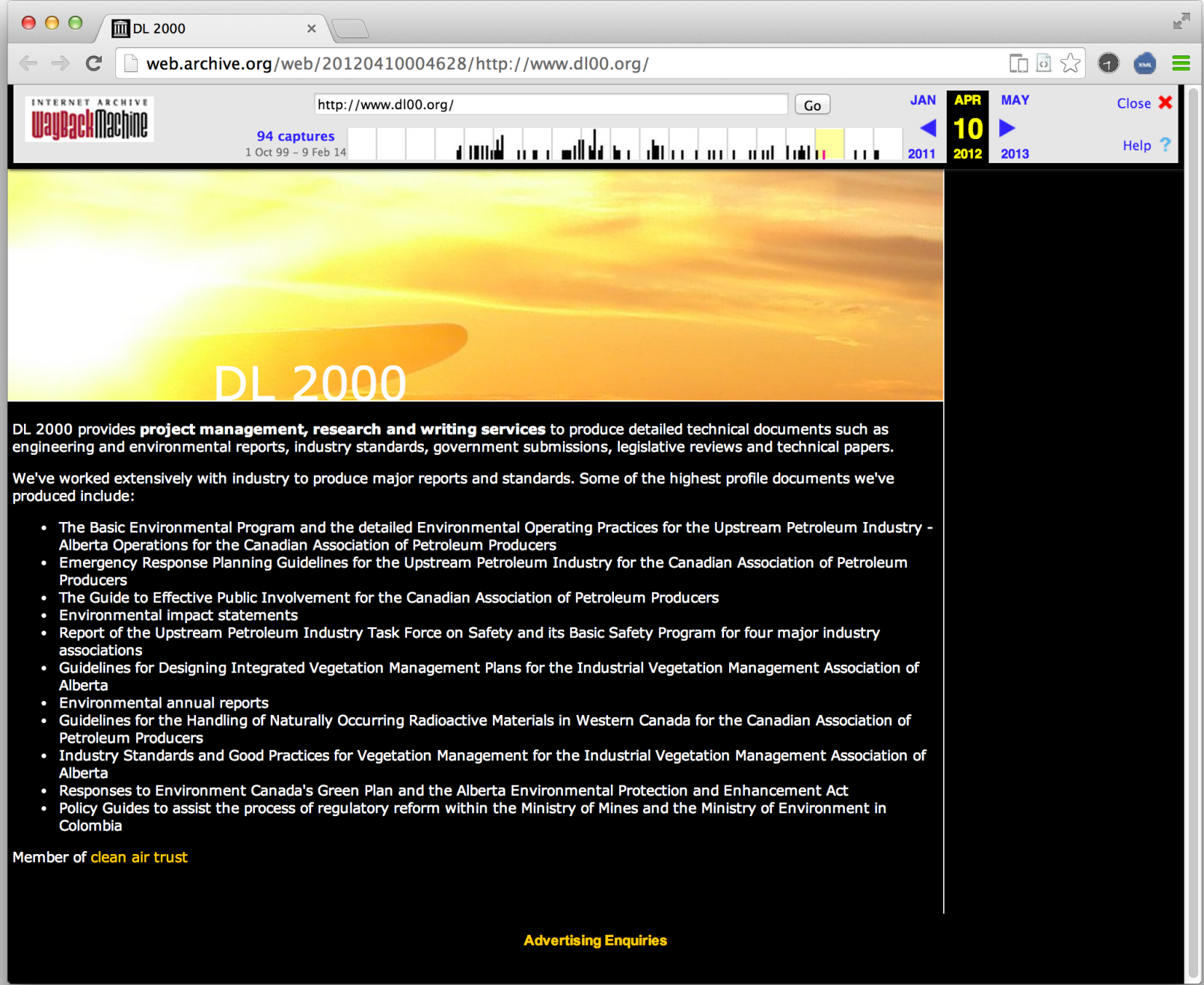

\section{http://dl00.org}

2008 


\section{Reference Rot}

- Link Rot: Link stops working e.g., HTTP 404

- Content Drift: Linked content changes over time

- Reference Rot $=$ Link Rot + Content Drift

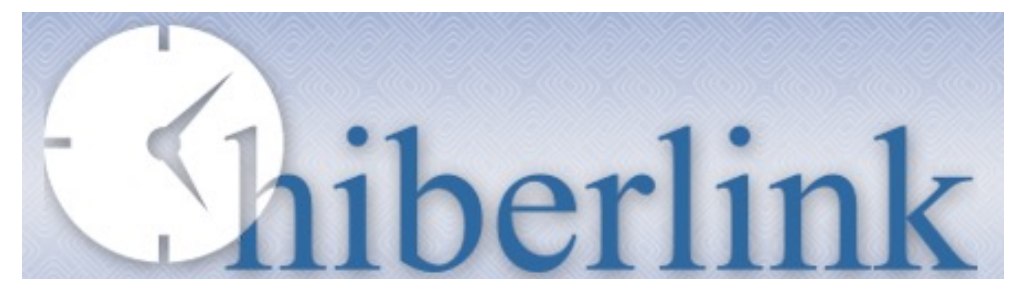

http://hiberlink.org/ 


\section{Reference Rot in scholarly communication}

- Web resources referenced in scholarly articles:

- Are subject to reference rot just like any other web resource.

- Are not necessarily under the custodianship of parties that care about long term integrity and access.

- Do not necessarily have the same sense of fixity that, for example, journal articles have. 


\section{Who cares?}




\section{The New York Times Cares}

SIDEBAR

In Supreme Court Opinions, Web Links to Nowhere By ADAM LIPTAK

Published: September 23, 2013

WASHINGTON - Supreme Court opinions have come down with a bad case of link rot. According to a new study, 49 percent of the hyperlinks in Supreme Court decisions no longer work.

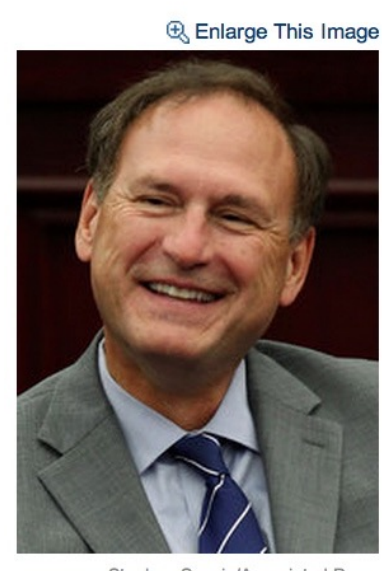

This can sometimes be amusing. A link in a 2011 Supreme Court opinion about violent video games by Justice Samuel A. Alito Jr. now leads to a mischievous error message.

“Aren't you glad you didn't cite to this Web page?" it asks. "If you had, like Justice Alito did, the original content would have long since disappeared and someone else might have come along and purchased the domain in order to make a comment about the transience of linked information in the Internet age."

Justice Samuel A. Alito Jr.

The prankster has a point. The modern Supreme Court opinion is increasingly built on sand.

Hyperlinks are a huge and welcome convenience, of course, said Jonathan Zittrain, who teaches law and computer science at Harvard and who prepared the study with Kendra Albert, a law student there. "Things are readily accessible," he said, "until they aren't."

\section{Links in Supreme Court}

decisions:

- Link rot: $29 \%$

- Reference rot: $49.9 \%$

http://www.nytimes.com/2013/09/24/us/politics/in-supreme-court-opinions-clicks-that-lead-nowhere.html 


\section{The Supreme Court should care}

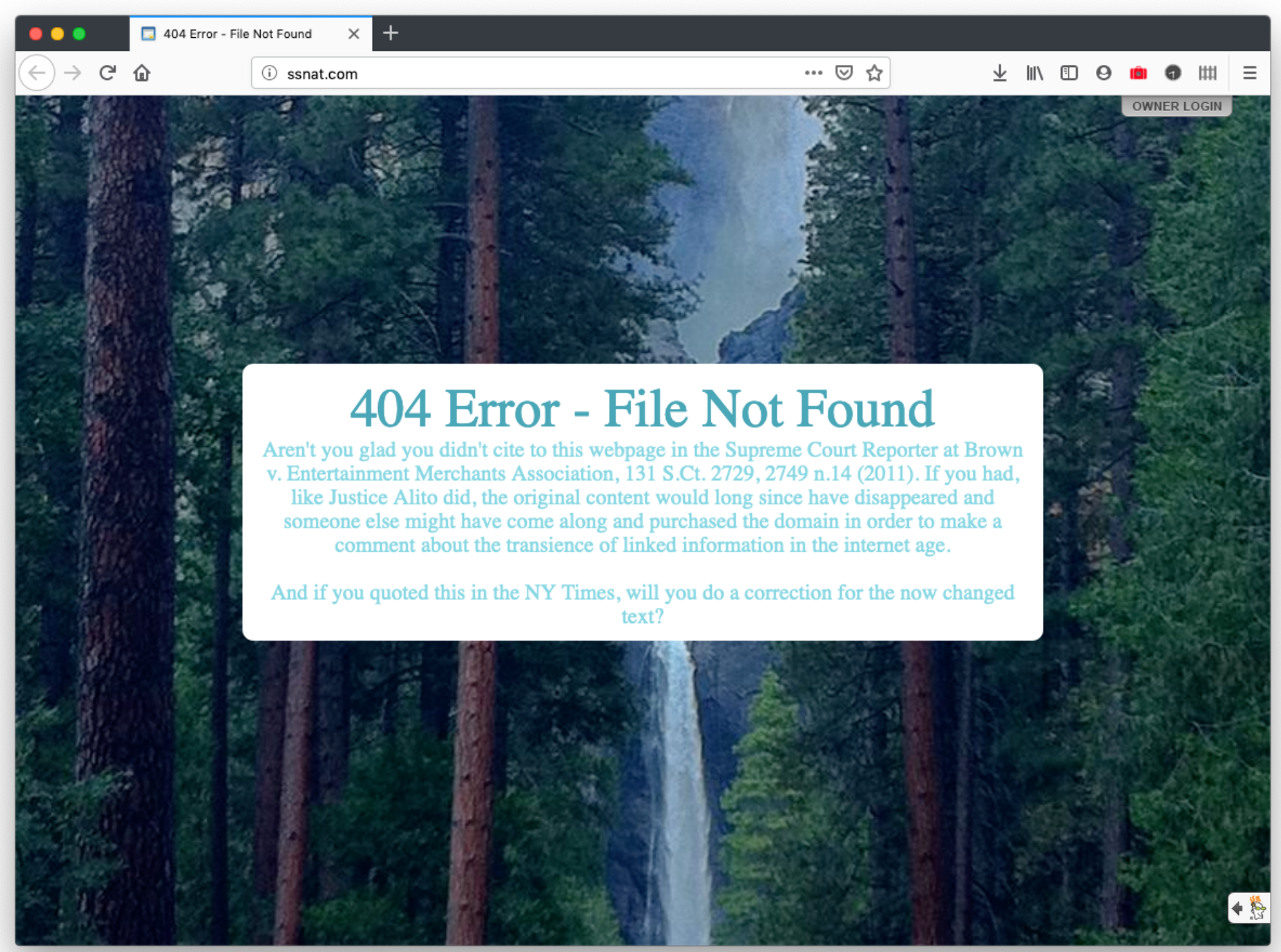

http://ssnat.com/ 


\section{Everybody should care}

\section{$12 / 2016$}

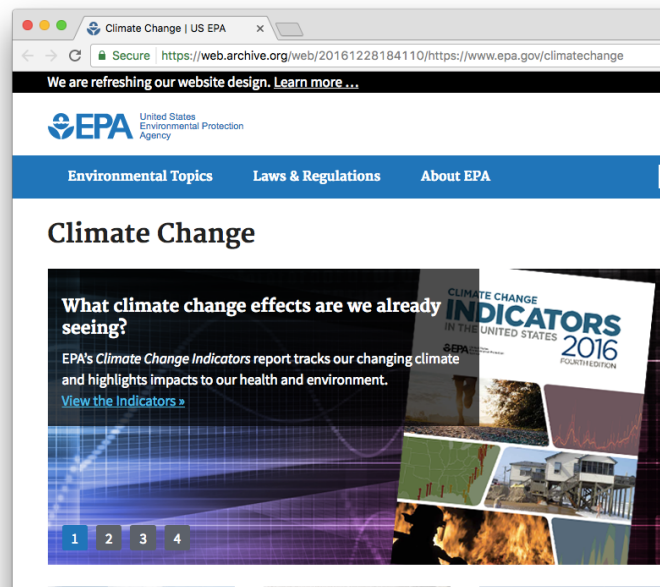

\section{TaN $\div \div$}

https://web.archive.org/web/20161228184110/ https://www.epa.gov/climatechange

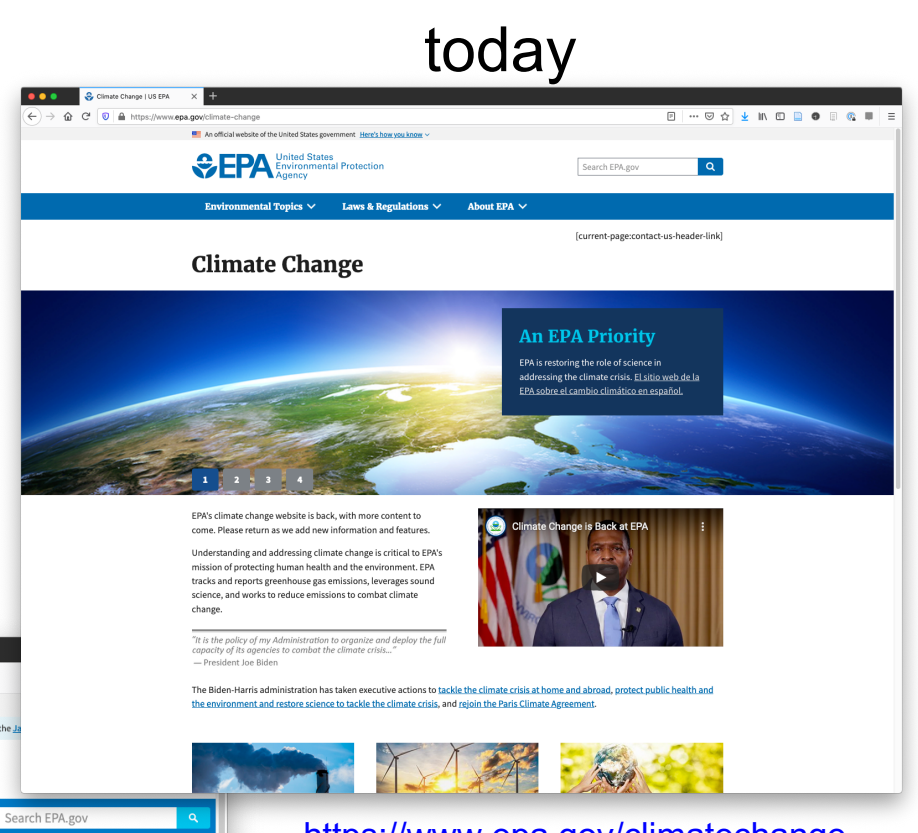

- See our A-Zlist of website topics

@mart1nkle1n

OA Week, LANL, 10/27/2021
Sorry, but this web page is not available for viewing right now

This page is not available for viewing beccuuse EPA

- Search frequently asked questions or submita question

- Goto the EPA home page

- To report problems wi

page.

You can also search our website. What are you looking for?
\begin{tabular}{|l|l|l|}
\hline climate change & Search EPA.gov & Search EPA Web Archives \\
\hline
\end{tabular}

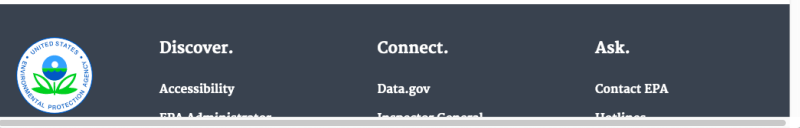

http://web.archive.org/web/20201027183049/

https://www.epa.gov/climate-change

\section{Robustify Your Links!}

https://www.epa.gov/climatechange 


\section{Authors should care}

\section{References}

D-Lib Magazine

September 200

Volume 10 Number 9

ISSN 1082-9873

Rethinking Scholarly Communication Building the System that Scholars Deserve

Herbert Van de Sompel

Los Alamos National Laboratory, Research Library

$<$ herbertv@lanl.gov>

Sandy Payette

Cornell University, Computing and Information Science

$<$ payette@cs.cornell.edu>

John Erickson

lett-Packard Laboratories, Digital Media Systems Lab $<$ john.erickson@hp.com>

Carl Lagoze

Und Computing and Information Science $<$ lagoze@cscornell.edu>

Simeon Warner

Cornell University, Computing and Information Science <simeon@cs.cornell.edu>

https://doi.org/10.1045/september2004vandesompel
Atkins, D. et al.. 2003. National Science Foundation Blue-Ribbon Advisory Panel on Cyberinfrastructure,

!Exist

Revolutionizing Science and Engineering through Cyber-infrastructure,

$<$ http://www.communitytechnology.org/nsf_ci_report/>.

Brody, T., Kampa, S., Harnad, S., Carr, L. and Hitchcock, S. 2003. Digitometric Services for Open

!Exist

Archives Environments. In Proceedings of European Conference on Digital Libraries 2003, pages pp. 207 220, Trondheim, Norway. <http://eprints.ecs.soton.ac.uk/archive/00007503/>.

!Exist

Frey, J., De Roure, D. and Carr, L. 2002. Publication at Source: Scientific Communication from a

Publication Web to a Data Grid. <http://eprints.ecs.soton.ac.uk/archive/00007852/>.

Henry, G. 2003. On-line publishing in the 21-st Century: Challenges and Opportunities. D-Lib Magazine Volume 9, Issue 10. <doi:10.1045/october2003-henry>.

!Exist

Lynch, C. 2003. Institutional Repositories: Essential Infrastructure for Scholarship in the Digital Age. ARL Bimonthly Report 226. February 2003, <http://www.arl.org/newsltr/226/ir.html>.

!Exist

Payette, S., and Staples, T. 2002. The Mellon Fedora Project: Digital Library Architecture Meets XML and Web Services. European Conference on Research and Advanced Technology for Digital Libraries, Rome, Italy, September 2002. <http://www.fedora.info/documents/ecdl2002final.pdf>.

Pöschl, U. 2004. Interactive Journal Concept for Improved Scientific Publishing and Quality Assurance. Learned Information, Volume 17, Number 2, pp 105-113. <doi:10.1087/095315104322958481>.

Reich, V. and Rosenthal, D. 2001. LOCKSS: A Permanent Web Publishing and Access System. D-Lib Magazine, Volume 7, Issue 6. <doi:10.1045/june2001-reich>.

Roosendaal, H., and Geurts, P. 1997. Forces and functions in scientific communication: an analysis of their

Exist interplay. Cooperative Research Information Systems in Physics, August 31-September 4 1997, Oldenburg, Germany. <http://www.physik.uni-oldenburg.de/conferences/crisp97/roosendaal.html>. 


\section{OK, so what are we going to do about it?}




\title{
Robust Links
}

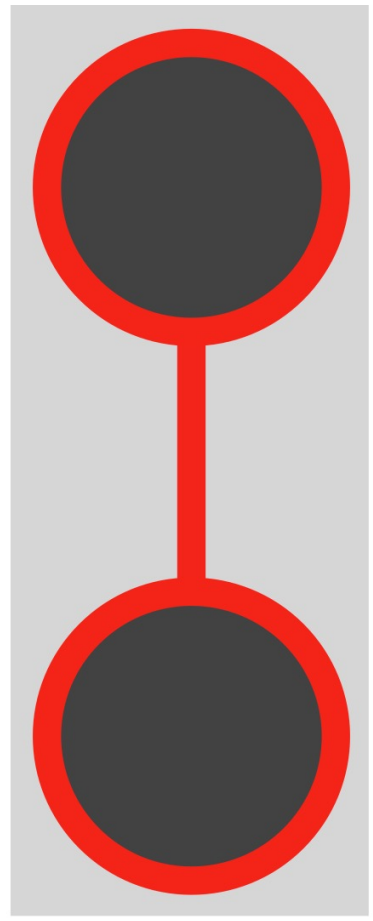

\begin{abstract}
https://robustlinks.mementoweb.org/ https://robustlinks.mementoweb.org/about/ https://robustlinks.mementoweb.org/spec/
\end{abstract}

"Robustifying Links To Combat Reference Rot" https://journal.code4lib.org/articles/15509 


\section{Robust Links}

1. Create a snapshot of referenced resources in a public web archive

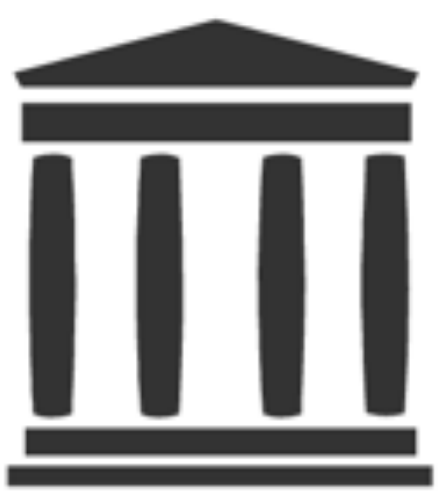

http://web.archive.org/

\section{archive.is webpage capture}

https://archive.md/

\section{perma.cc}

https://perma.cc/ 


\section{Robust Links}

1. Create a snapshot of referenced resources in a public web archive

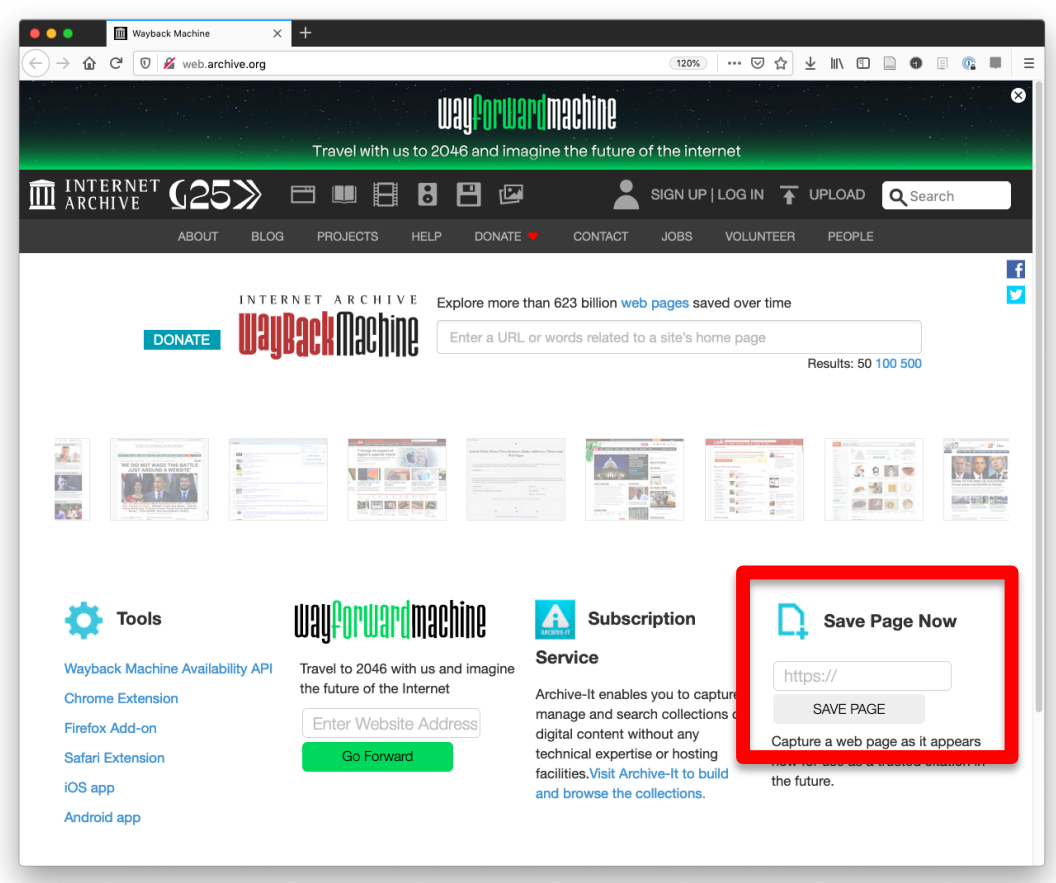

http://web.archive.org/
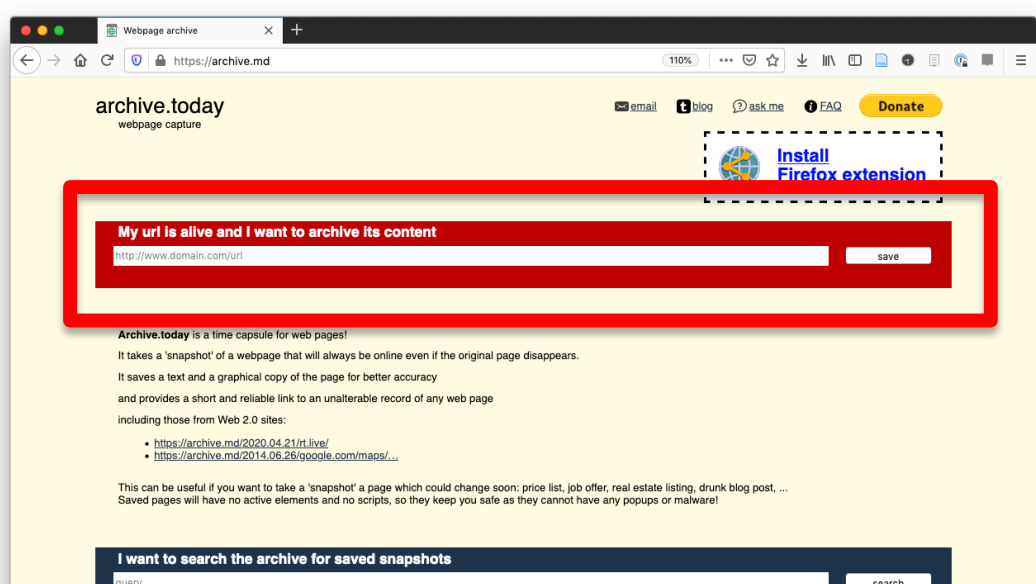

search

search queries by example

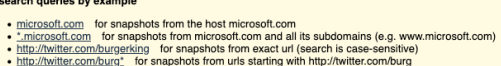

https://archive.md/ 


\section{When to create an archival copy?}

- As close as possible to the time of linking!

- Aka time of writing

- By the author

- Or at the time of:

- Submission

- conference or journal submission systems

- Publication

- commercial publishers, pre-prints

- Aggregation, "Consumption"

- $\quad 3^{\text {rd }}$ party such as CORE, institutional repositories 


\section{Common Practice}

Capture datetime

^ Heyerdahl 1961 However, Alfred Metraux pointed out that the rubble filled Rapanui walls were a fundamentally different design to those of the Inca, as these are trapezoidal in shape as opposed to the perfectly fitted rectangular stones of the Inca. See also this FAQ

URL of archived snapshot

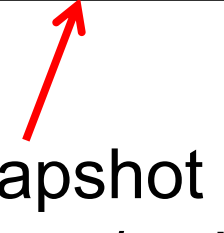

https://web.archive.org/web/20071011083729/http://islandheritage.org/faq.html

- Link to (ideally) immutable memento

- Original URL "visible" 


\section{But what if...}

URL of created snapshot is:

- $\quad$ http://archive.is/MTMKu

- $\quad$ https://perma.cc/9265-T4NB

- $\quad$ https://www.mummify.it/XbmcMfE3

- It is impossible to visit the original URI, if desired

- It requires the permanent existence/uptime of the archive that holds the snapshot

$\rightarrow$ One link rot problem replaced by another 


\section{Robust Links}

1. Create a snapshot of referenced resources in a publically available web archive

2. Robustify links with:

- URL of archived snapshot (memento)

- datetime of archiving/linking

- original URL of resource

Benefits:

- Can visit live version of referenced resource

- Can visit created memento of referenced resource

- Original URI + capture datetime allows finding an appropriate capture in all web archives

- Uniform, machine-actionable 


\section{HTML Link}

<a href="http://www. whitehouse.gov"

The White House</a $>$

http://robustlinks.mementoweb.org/spec 


\section{Robustified Link}

<a href="http://www.whitehouse.gov"

data-versionurl="https://perma.cc/9265-T4NB" data-versiondate $=" 2015-11-18 ">$

The White House $\langle/ a\rangle$

http://robustlinks.mementoweb.org/spec 


\section{Robustified Links}

<a href="https://perma.cc/9265-T4NB"

data-originalurl="http://www.whitehouse.gov" data-versiondate $=" 2015-11-18 ">$

The White House $\langle/ a\rangle$

http://robustlinks.mementoweb.org/spec 


\section{Link Decoration in Action}

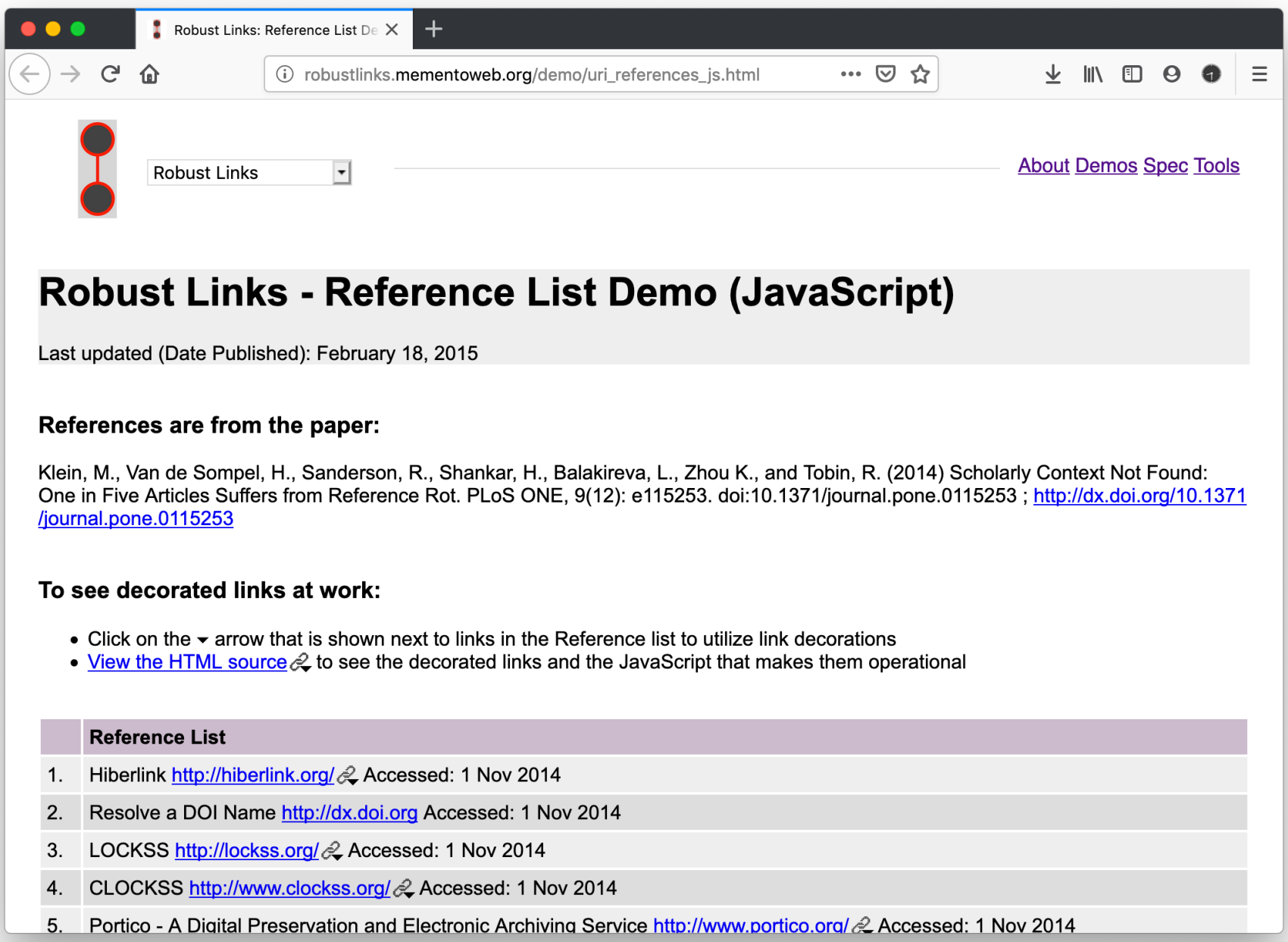

http://robustlinks.mementoweb.org/demo/uri references js.html 


\section{Help creating Robust Links?}




\section{https://robustlinks.mementoweb.org/}

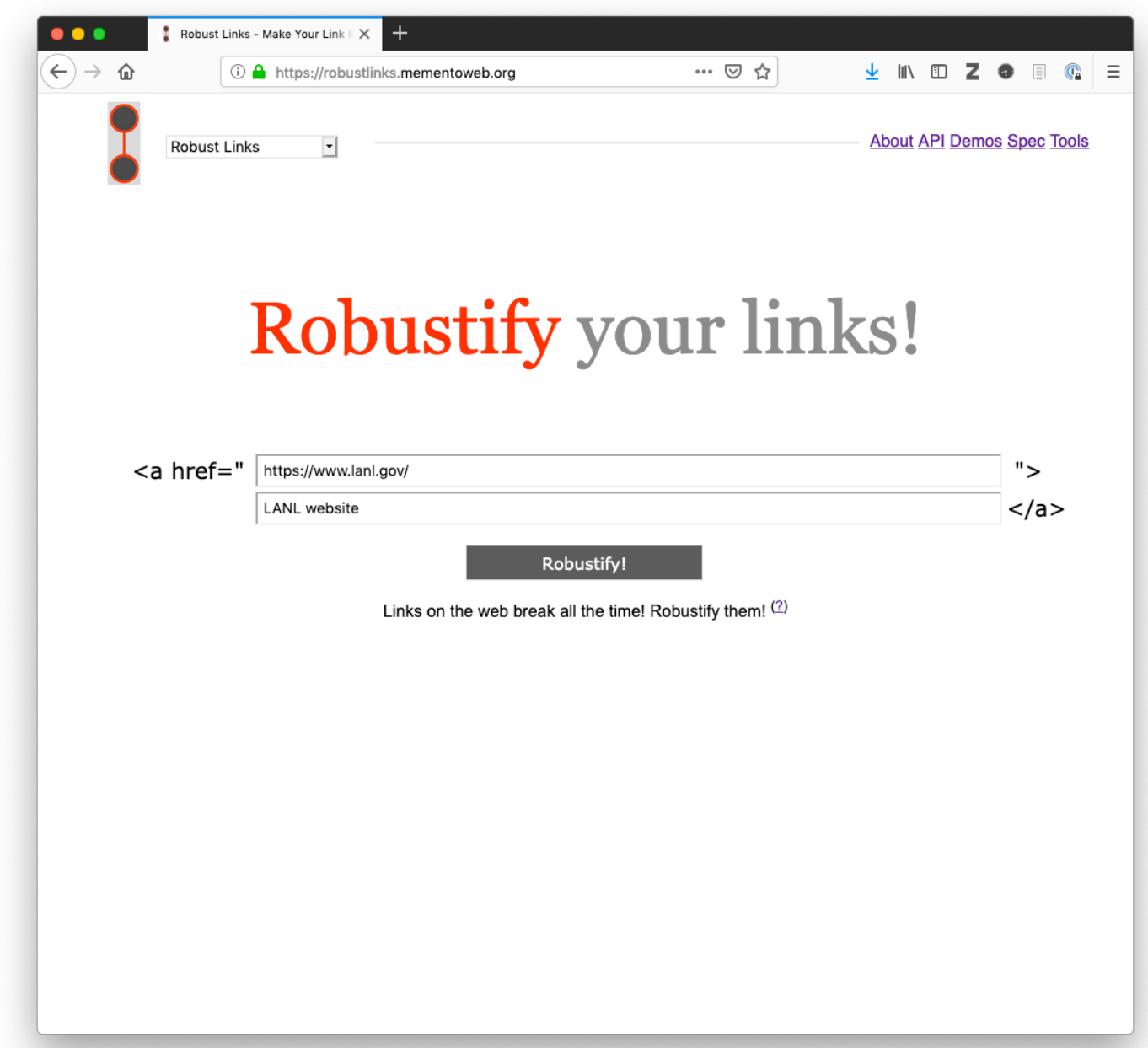




\section{https://robustlinks.mementoweb.org/}

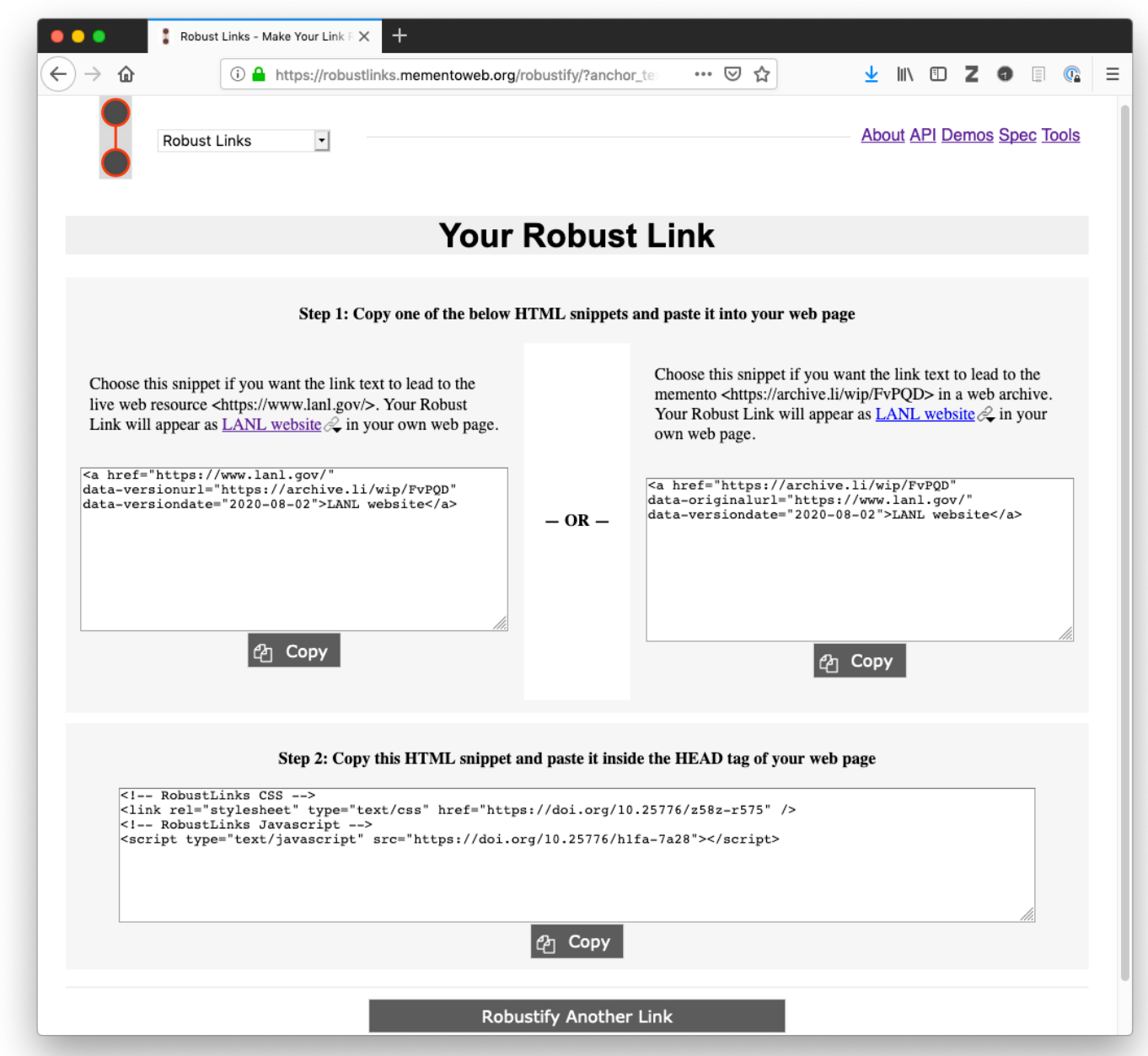




\section{https://robustlinks.mementoweb.org/api-docs/}

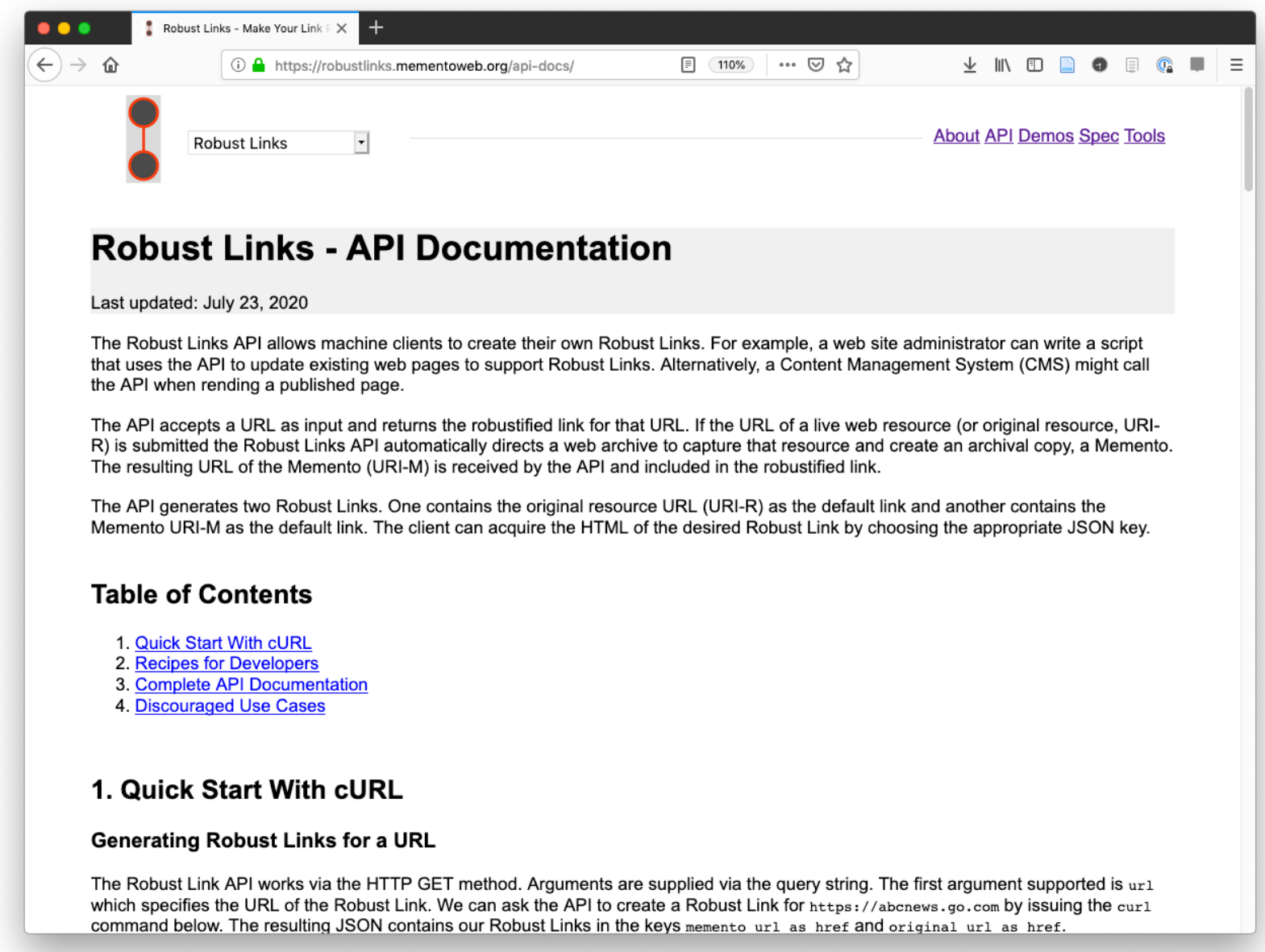




\section{Zotero Robust Links Extension}

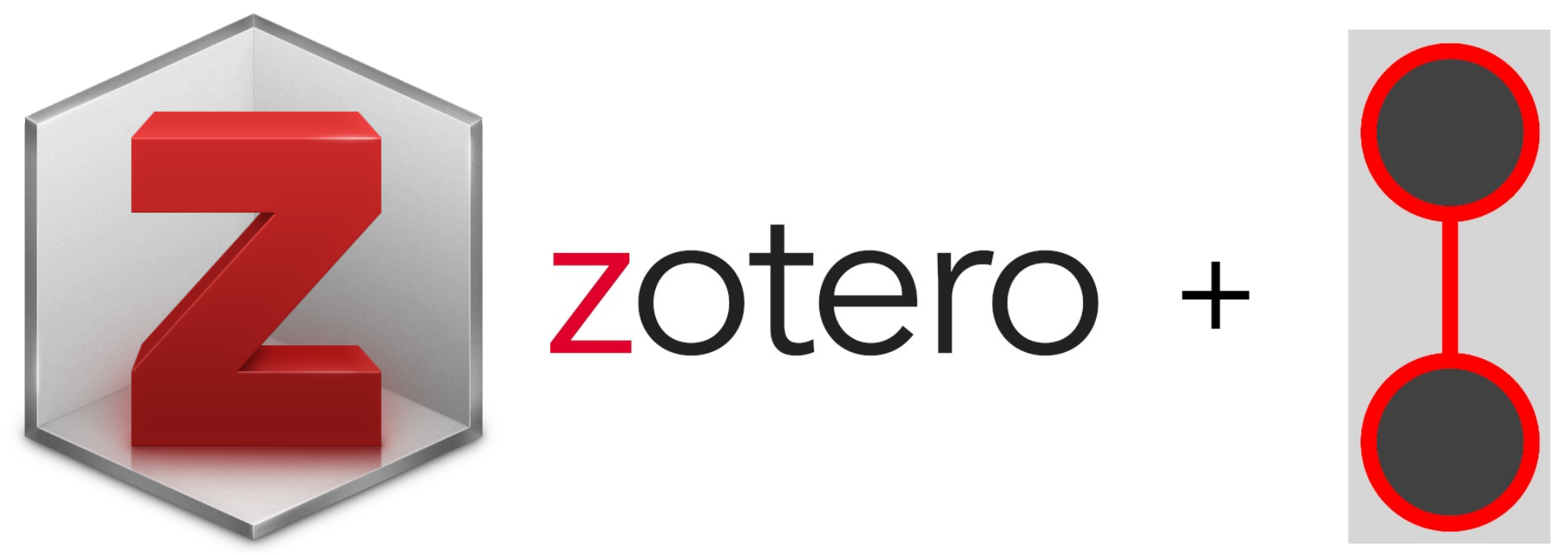

https://robustlinks.mementoweb.org/zotero/

https://github.com/lanl/Zotero-Robust-Links-Extension 


\title{
Robustify Your Links! For better stewardship of references to web resources in digital scholarship
}

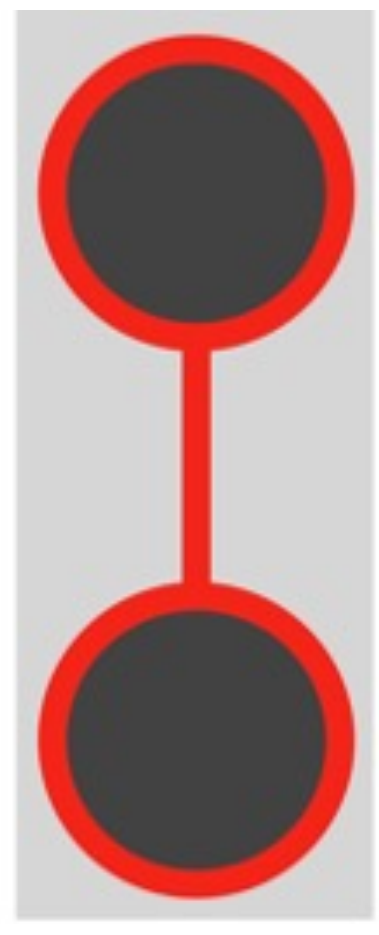

\author{
Martin Klein \\ mklein@lanl.gov \\ @mart1nkle1n \\ http://orcid.org/0000-0003-0130-2097
}

Research Library

Los Alamos National Laboratory

<a href="http://www.whitehouse.gov"

data-versionurl="https://perma.cc/9265-T4NB" data-versiondate $=" 2015-11-18 ">$

The White House</a> 